\title{
Utilização de galinheiro móvel na comunidade do Amaragi, Lagoa Seca-Paraíba
}

\author{
Weslley de Assis Silva ${ }^{1}$, Fabricio Gomes de Andrade ${ }^{1}$, Raniery Santiago Cantalice ${ }^{1}$, Thiago Bernardino de Sousa \\ Castro $^{2}$, Thiago do Nascimento Coaracy ${ }^{3}$ \\ ${ }^{1}$ Universidade Estadual da Paraíba, weslleyanjospb@gmail.com, gomez.agroe@gmail.com; \\ ranierycantalice@gmail.com ${ }^{2}$ Universidade Federal de Campina Grande thiagopbpe@gmail.com; \\ ${ }^{3}$ Universidade Federal da Paraíba, thiago.coaracy@gmail.com.
}

\begin{abstract}
RESUMO: O relato de experiência foi realizado no município de Lagoa Seca-PB, na comunidade do Amaragi no "Nosso Sítio" com produtores familiar em transição de Lagoa Seca -PB, com a colaboração por alunos do curso de agroecologia e agropecuária na Universidade Estadual da Paraíba - UEPB. Está experiência do galinheiro móvel as aves ficaram em fase de adaptação e, posteriormente foram colocadas dez galinhas em fase reprodutiva e um galo adulto. As galinhas permaneceram durante 15 dias em cada área escolhida e posteriormente eram colocadas em outra área que estava em pousio. Visualizou-se que as aves dentro do galinheiro móvel se alimentavam e ciscavam toda a área possibilitando a limpeza das ervas adventícias e incrementaram de material orgânico proveniente dos excrementos ricos em nitrogênio que é um elemento primordial para uma boa fertilização. As aves criadas em consórcio com hortas visando alimentação alternativa para as aves, facilitar o airado do solo, deixando-o adubado e agregado, para em seguida promover o levantamento dos canteiros no tamanho do galinheiro móvel desejado.
\end{abstract}

PALAVRAS-CHAVE: Avicultura; Sustentabilidade; Permacultura.

\section{CONTEXTO}

A agricultura familiar predomina em grande parte da região Paraibana. O agricultor além de plantar, geralmente tem criações de animais de grande e pequeno porte. Esta diversificação das atividades produtivas é a chave para o agricultor familiar tanto na geração de renda como na soberania alimentar. Dentre os animais de pequeno porte predomina a criação de aves nativas (SRD), conhecidas por galinha de capoeira.

Esta criação ocorre primeiramente pelas questões socioculturais e pela rusticidade das galinhas de capoeira criadas nesta região, Neves (2005) aponta que o ciclo de produção é rápido, proporcionando retorno num período relativamente curto e contribuindo diretamente para a fixação do homem ao campo.

Dentre as alternativas para fixação do homem do campo é a agroecologia, Guzmán (2001) relata que a agroecologia propõe um desenho de métodos de desenvolvimento endógeno para o manejo ecológico dos recursos naturais, utilizando os elementos de resistência específicos de cada identidade local, baseando-se na sistematização, análise dos elementos de resistência locais frente ao processo de modernização, para, através deles, desenhar, de forma participativa, estratégias de desenvolvimento definidas a partir da própria identidade local do etnoecossistema concreto em que se inserem.

Tendo a Permacultura como uma metodologia de desenhos de ambientes humanos sustentáveis, ela dá suporte para criação de ambientes para viver em harmonia com a natureza. Consiste no manejo permanente do solo com objetivo de autossuficiência sustentável mantendo todos os elementos e seres integrados no ecossistema, (MOLLISON, E HOLMGREY. 1979).

A permacultura por ser uma ciência interdisciplinar, dentre as suas práticas tem a utilização dos galinheiros móveis, uma alternativa para solucionar a problemática enfrentado nas comunidades rurais das aves soltas que ciscam livremente as áreas agricultáveis, gerando até confusões entre agricultores.

Tendo em vista a importância da criação de galinhas para a agricultura familiar esta experiência objetivou avaliar a eficácia destes galinheiros móveis em áreas de pousio de galinheiros móveis na comunidade rural do Amaragi em Lagoa Seca-PB.

\section{METODOLOGIA}

Após a fase de adaptação das aves no galinheiro móvel (figura 1 e 2), foram colocadas dez galinhas em fase reprodutiva e um galo adulto. As galinhas permaneceram durante 15 dias em cada área escolhida e posteriormente eram colocadas em outra área que estava em pousio. A água foi fornecida para os animais via bebedouro, para alimentação foi ofertada milho em grão. 
SILVA, A. W. et al. Utilização de Galinheiro móvel na Comunidade do Amaragi, Lagoa Seca-PB,In: II Congresso Paraibano de Agroecologia \&IV Exposição Tecnológica, 2019. Anais... Caderno Verde de Agroecologia e Desenvolvimento Sustentável, Pombal, v. 9, n.7, e- $6704,2019$.

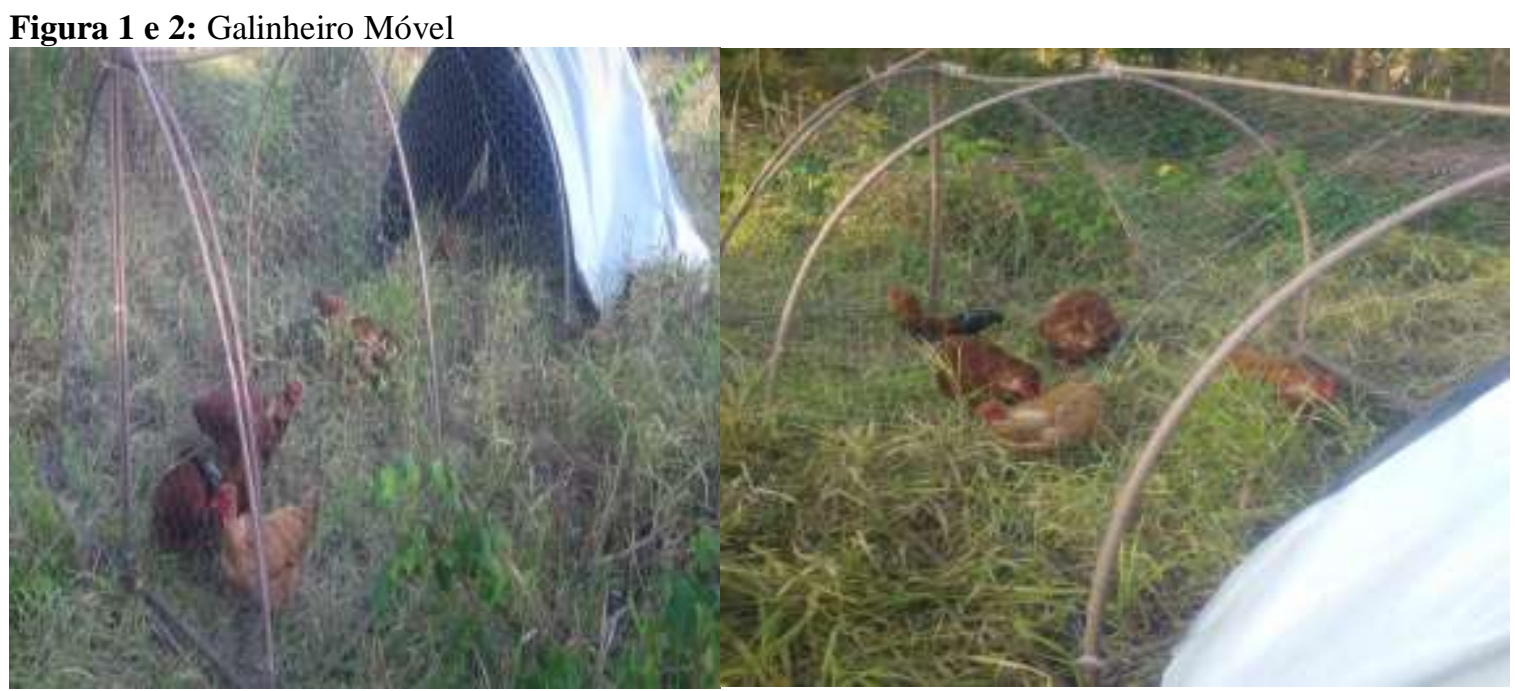

\section{DESCRIÇÃO DA EXPERIÊNCIA}

O relato de experiência ocorreu através de reuniões, encontros e práticas seguindo princípios da agroecologia e permacultura, em parceria com o Campus II da UEPB junto ao núcleo de Extensão Rural (NERA), Lagoa Seca-PB em parceria com 'Nosso Sítio'.

Deve-se ter em mente para a construção do galinheiro móvel a utilização de matérias o aproveitamento de tábuas, telhas, bambu, pinus, apesar de todas essas alternativas, quando não é possível a utilização de material reutilizável deve-se partir para o galinheiro móvel em estrutura metálica, visando sempre o conforto térmico para os animais.

Cada galinheiro móvel foi confeccionado com canos de pvc $20 \mathrm{~mm}$, cola, tela galvanizada tipo (pinteiro), e arames para fazer amarrações, lona para cobertura, cuja dimensões são $5 \mathrm{~m}$ de comprimento com $1 \mathrm{~m}$ de largura e $1,5 \mathrm{~m}$ de altura, onde. a construção da tecnologia alternativa foi realizado em mutirão com agricultores e criadores da comunidade. Nesse experimento foram utilizadas 10 galinhas de capoeiras em cada galinheiro e um galo. O objetivo dos galinheiros móveis foi realizar limpeza de uma determinada área pelas aves onde as mesmas passaram de 12 há 15 dias sendo alimentadas com a vegetação local, juntamente com uma suplementação com oferta do milho em grão) e água tratada. As aves ciscaram todo perímetro dentro galinheiro.

\section{RESULTADOS}

Com o passar do tempo, visualizou-se que as aves dentro do galinheiro móvel ingeriam alimentos e ciscavam toda a área, possibilitando assim a limpeza das ervas adventícias e incrementarão de material orgânico proveniente dos excrementos ricos em nitrogênio que é um elemento primordial para uma boa fertilização.

As aves apresentam função fertilizante para o agroecossistema, pois os nutrientes consumidos pelas aves são transferidos para o solo e as plantas na forma de esterco, as galinhas apresentam hábito de ciscar (revolvem a terra com as patas), além de realizar a limpa do local comendo diversos microrganismos (GUELBER-SALES, 2005). O esterco produzido pelas galinhas pode ser utilizado na horticultura diretamente sobre o solo, e ficando a área limpa para o plantio (figura 3 e 4 ).

Figura 3 e 4: Área limpa pelas aves

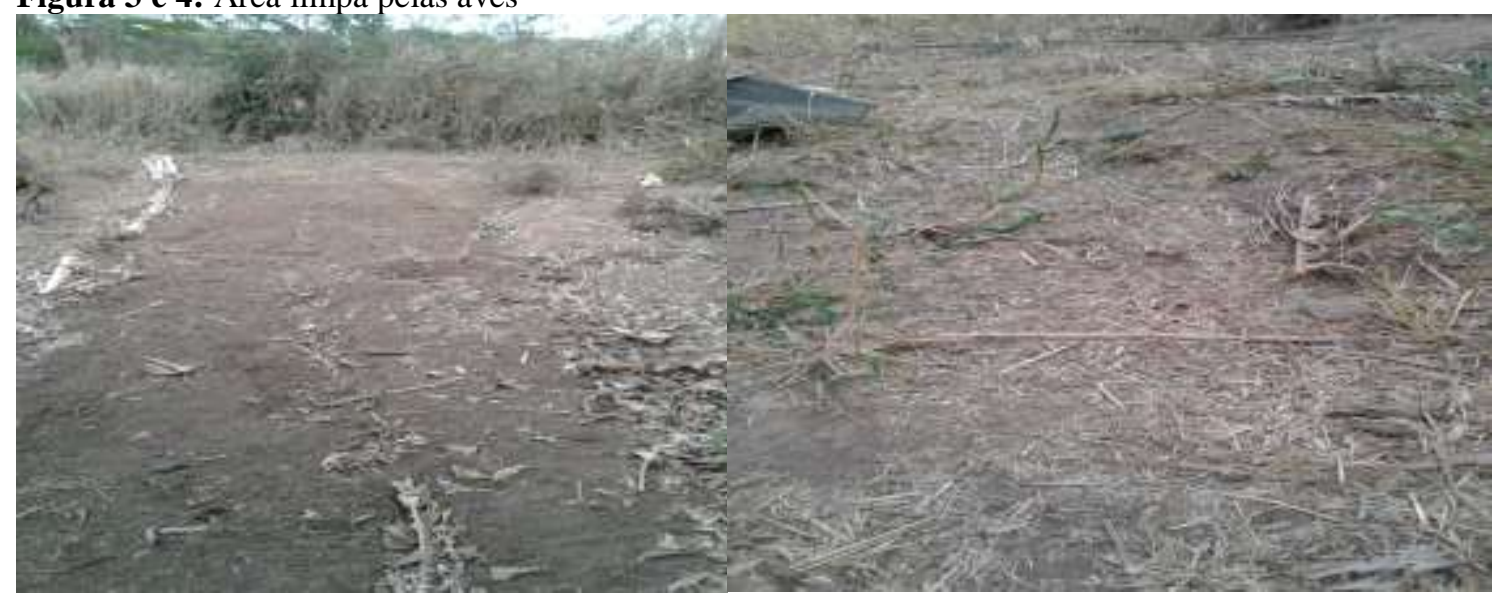


SILVA, A. W. et al. Utilização de Galinheiro móvel na Comunidade do Amaragi, Lagoa Seca-PB,In: II Congresso Paraibano de Agroecologia \&IV Exposição Tecnológica, 2019. Anais... Caderno Verde de Agroecologia e Desenvolvimento Sustentável, Pombal, v. 9, n.7, e- $6704,2019$.

Além de fornecer esterco aos cultivos, a avicultura aproveita os restos de plantios e dos refugos de frutas e hortaliças. Assim, a atividade que tradicionalmente é administrada pelas mulheres e jovens agricultores passa a ter o seu papel reconhecido na geração de renda e valorizada como forma de ocupação (NEVES, 2005).

Segundo Garcia et al. (2002), existe uma demanda crescente por sistemas de produção que assegurem uma qualidade e manutenção do bem-estar das aves, viabilizando um produto de excelência, compatível com exigência de qualidade e segurança alimentar. O galinheiro móvel vem a contribuir para o bem-estar animal pois as aves semiconfinadas tem contato direto com o solo e o pasto para ciscarem.

\section{CONCLUSÃO}

As aves criadas em consórcio com hortas visando alimentação alternativa para as aves, facilitará o airado do solo, deixando-o adubado e agregado, para em seguida promover o levantamento dos canteiros no tamanho do galinheiro móvel desejado.

O galinheiro móvel apresenta diversas vantagens: como locomoção utilizando no máximo duas pessoas, fácil confecção por ser confeccionado por todos os membros familiares, permite a recuperação da cobertura do solo e melhor aproveitamento da área e das pastagens disponíveis além de colaborar com a estrutura química e física do solo.

Muitos estudos estão sendo elaborados para criação de galinheiros móveis, pois apesar de existir toda uma facilidade na criação das galinhas caipiras livremente, essa facilidade não as protegem de ataque de predadores, mortalidade elevada dos pintos, por isso a necessidade da criação de galinheiros móveis. Tendo em vista a importância da criação de galinhas para a agricultura familiar esse trabalho capacitoude agricultores familiares para confecção de galinheiros móveis na comunidade rural do Amaragi em Lagoa Seca-PB, de esta forma os animais poderam ter contato com o solo e não prejudicar as hortas dos agricultores.

\section{REFERÊNCIAS}

GARCIA, R. G., CAldARA, F. R., ABREU, A. P. N. DEMATTÊ FILHO, L.C.D., PEDROSA, J. M. Y. Perspectivas de Mercado do Frango certificado Alternativo no estado de São Paulo-Botucatu: Faculdade de Medicina Veterinária e Zootecnia, 2002. p.32.

GUZMAN, S.; Agroecologia e Desenvolvimento Rural Sustentável. Porto Alegre, v.2, n.1, jan./mar.2001. 30 p.

MOLlisON, B.; HOLMGREY, D. Permacultura um. Rio de Janeiro : Ground, 1979.

NEVES, M., GUELBER SALES,M.N.,HOFFMANN,R.B., OLIVEIRA,R.D., SALES,E.F.* Revalorizando as pequenas criações na agricultura familiar Capixaba Agriculturas - v. 2 - no 4 - dezembro de 2005.

GUELBER SALES, M.N. Sistematização das experiênciasdos PRRS - Pólos de reprodução da raça Sorocaba. Vitória: Incaper, 1996. 18 p.Mimeografado [3] Revista Sebrae Agronegócios - $\mathrm{n}^{\mathrm{o}} 7$ - Dezembro de 2007, acessado em 14/08/2019, disponível em http://www.rts.org.br/noticias/destaque-4/caipira-que-da-lucro.

\section{AGRADECIMENTOS}

Apoio financeiro: Fundação de Apoio à Pesquisa do Estado da Paraíba - FAPESQ. 